\title{
Analysis of risk factors for presacral abscess after radical resection of middle and low rectal cancer.
}

\section{Ang Li}

Shuguang Hospital

Jun Shi

Yixing People's Hospital

\section{Binqiao Shi}

Second Military Medical University

Xiaohui Shi ( $\nabla$ drshixh@sina.com )

First Affiliated Hospital of Naval Medical University https://orcid.org/0000-0002-4025-1715

\section{Research}

Keywords: Rectal cancer, Presacral abscess, Radical resection, Risk factors

Posted Date: October 1st, 2021

DOl: https://doi.org/10.21203/rs.3.rs-917464/v1

License: (c) (i) This work is licensed under a Creative Commons Attribution 4.0 International License. Read Full License 


\section{Abstract}

Background and Objectives

To investigate the risk factors of presacral abscess after radical resection of middle and low rectal cancer.

Methods

Clinical data of 2279 patients with middle and low rectal cancer in the department of Colorectal Surgery at the Changhai Hospital of the Second Military Medical University from January 2015 to December 2018 were analyzed retrospectively. Univariate and multivariate analyses were performed to find the risk factors of presacral abscess using Chi-square test and Logistic regression, respectively.

Results

The median age of all cases was 62 years. Of the 27 cases with presacral abscess, 22 were males and 5 were females. 12 cases were low rectal cancer and 15 cases were middle rectal cancer. Univariate Chisquare test indicated that the relative factors associated with the presacral abscess were tumor size, operative time, blood loss, $\mathrm{T}$ stage lesions, receiving preoperative radiotherapy and with preventive terminal ileostomy. Multivariate analysis showed that tumor size, operative time, blood loss, receiving preoperative radiotherapy and with preventive terminal ileostomy were the independent risk factors.

Conclusions

Patients with big tumor size, long operative time, high blood loss and preoperative radiotherapy are highrisk groups of presacral abscess after radical resection of middle and low rectal cancer.

\section{Introduction}

The incidence of anastomotic leakage in low rectal cancer is $10 \%-20 \%$ [1]. There is no clear definition of the difference between anastomotic fistula and presacral abscess, according to the International Study Group of Rectal Cancer(ISGRC), the abscess near the anastomotic site is also anastomotic leakage [2]. However, some scholars think that the CT scan show abscess located in the presacral area, without leakage of contrast agent from the intestinal tract or other anastomotic leakage symptoms, is defined as a presacral abscess (PA) [3]. If the conservative treatment is ineffective, the secondary operation may cause serious complications, even death [4]. It is of great clinical significance to evaluate the risk of presacral abscess after radical resection of middle and low rectal cancer. Due to the low incidence of presacral abscess after rectal cancer surgery, there are few reports in this field. In this study, the clinical data of patients with middle and low rectal cancer were analyzed retrospectively to explore the high-risk factors of presacral abscess after radical operation of middle and low rectal cancer.

\section{Materials And Methods}


The inclusion criteria were as follows: (1) rectal cancer was diagnosed by electronic colonoscopy, pathological biopsy, and abdominal imaging before operation; (2) radical resection was performed; (3) adenocarcinoma or mucinous adenocarcinoma was confirmed by pathology after operation; (4) the distance between tumor and anal margin was less than $7 \mathrm{~cm}$ according to colonoscopy before operation.

The exclusion criteria were: (1) there was definite distant metastasis before operation; (2) there were other multiple primary tumors before operation; (3) there was complete intestinal obstruction before operation; (4) cases with positive CRM that can not be complete resected by preoperative MRI evaluation.

\section{Diagnosis criteria of presacral abscess}

After operation, persistent high fever or local or diffuse peritonitis was found. CT examination of pelvis indicated presacral abscess. At the same time, the following cases were excluded: (1) there were clear signs of anastomotic leakage, including $A$ : abdominal (basin) cavity drainage tube or abdominal incision drainage of intestinal contents, accompanied by increased body temperature or blood leukocyte elevation; B: gastrointestinal radiography suggested that the contrast agent leaked from the intestinal tube or the drainage tube; C: CT showed anastomotic edema or free gas shadow; D: rectal digital examination found low anastomotic leakage (2) CT showed presacral effusion, but ultrasound showed that the maximum diameter of presacral abscess was less than $2 \mathrm{~cm}$. The pelvic plain scan was performed by using the spiral CT scanner (64 rows). Two doctors with rich experience in the diagnosis of pelvic diseases independently observed and analyzed the images, and reached a consensus.

III. Case information

According to the above criteria, from January 2015 to December 2018, 2279 patients with middle and low rectal cancer were included in the study. There were 1470 males and 809 females, with a median age of $61(19-94)$ years. 27 patients $(2.86 \%)$ developed a presacral abscess.

\section{Statistical methods}

SPSS 20.0 statistical software was used to analyze the data. According to the patient's history, 10 variables, including sex, age, tumor location, tumor maximum diameter, operation time, bleeding volume, tumor invasion depth, lymph node metastasis, preoperative radiotherapy, and preventive terminal ileostomy, were included in the univariate analysis, using $\chi^{2}$ test or accurate probability method. The variables with $P<0.05$ in single factor analysis were added to the logistic regression model for further multi-factor analysis. $P<0.05$ indicated that the difference was statistically significant.

\section{Results}

Tumor size $\left(\chi^{2}=18.447, P=0.000\right)$ هoperative time $\square \chi^{2}=18.447, P=0.000$ هublood loss $\square \chi^{2}=30.388, P=$ 0.000 खाT stage lesions $\square \chi^{2}=18.447, P=0.000$ ख receiving preoperative radiotherapy $\square \chi^{2}=8.433, P=0.004$ 
Dand with preventive terminal ileostomy $\square \chi^{2}=13.432, P=0.000$ \is the relative factors associated with the presacral abscess of middle and low rectal cancer, as summarized in Table 1. Multivariate analysis showed that tumor size $O R$ : $0.211 \otimes 95 \% C / \otimes 0.086 \sim 0.520 \otimes P=0.001 \otimes$ operative

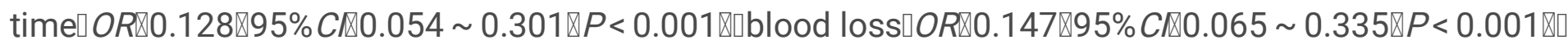
receiving preoperative radiotherapy $\triangle O R \otimes 0.195 \rrbracket 95 \% C / \otimes 0.069 \sim 0.549 \rrbracket P=0.002 \rrbracket$ and with preventive terminal ileostomy $\square O R \otimes 0.172 \rrbracket 95 \% C \otimes 0.063 \sim 0.472 \rrbracket P<0.001 \rrbracket$ were the independent risk factors of presacral abscess of middle and low rectal cancer, as summarized in Table 2.

\section{Discussion}

The risk factors of anastomotic leakage in rectal cancer are reported frequently,such as contamination of operation area and long operation time[5]. However, there are few studies on the presacral abscess. On the one hand, the incidence of presacral abscess after middle and low rectal cancer is relatively low; on the other hand, due to the relatively few cases in single-center, further standardization is required for the diagnosis and treatment measures. In this research unit, there were more than 1000 cases of middle and low rectal cancer surgery annually. Based on the statistics of the cases from January 2015 to December 2018, we collected the basic data of 27 PA patients and summarized the influencing factors of PA after middle and low rectal cancer surgery as follows for reference of professional colleagues. To study the high-risk factors of presacral abscess after radical operation of middle and low rectal cancer can prevent the high-risk factors, and strengthen the postoperative monitoring of high-risk patients in order to early diagnosis.

This study shows that operation time is an independent risk factor for presacral abscess after operation. The prolongation of operation time may be related to the difficulty of operation. On the one hand, the long operation time is related to the characteristics of the tumor itself. The operation of middle and low rectal cancer in the narrow pelvis is relatively difficult, the difficulty of the operation and the exposure time in the open abdomen will be increased by the reason of The relatively large tumor, both increase the chance of pollution of abdominal and pelvic significantly ${ }^{[6]}$. On the other hand, the long operation time may be related to the professionalism of the operating doctors and their teams, the incidence of postoperative complications of the specialists without systematic training is significantly high ${ }^{[7]}$.

Veenhof AA etal ${ }^{[8]}$ analyzed 261 cases of rectal cancer and pointed out that patients with preoperative radiotherapy or large tumor were prone to causing presacral abscess. Our data also showed that tumor size and preoperative radiotherapy were independent risk factors for presacral abscess after radical resection of middle and low rectal cancer. Preoperative radiotherapy leads to local edema, poor tissue healing ability, and susceptibility to infection, etc, these factors may jointly lead to the occurrence of presacral abscess ${ }^{[9]}$.

The results showed that the blood loss was an independent risk factor for presacral abscess. In this group, the incidence of presacral abscess was $0.63 \%$ in patients with low blood loss, which was significantly different from $4.0 \%$ in patients with high blood loss $(P<0.001)$.Vermeer TA etal[10]showed 
that rectal cancer patients with high intraoperative blood loss were more likely to develop presacral abscess after surgery, and the results were consistent with the data in this group. We consider that the blood loss is mostly related to tumor size and the operation standardization of the operator. High blood loss increases the incidence of local infection, poor postoperative nutritional condition, and resistance, all of these increase the incidence of presacral abscess.

This study suggests that patients undergoing preventive terminal ileostomy are more likely to develop presacral abscess after operation. By analyzing the reasons, we believe that patients at risk of anastomotic leakage will receive prophylactic terminal ileostomy and these risks promote the occurrence of presacral abscess.

The treatment of presacral abscess after the operation of middle and low rectal cancer is relatively difficult. Many literatures reported a series of methods, including conservative treatment, image-guided puncture, reoperation, etc. Each has its advantages and disadvantages. In our view, image-guided puncture drainage is an effective treatment for deep pelvic abscess [11],27 cases of presacral abscess in this group of data obtained good results after CT guided puncture and drainage. We will introduce our methods and experience in detail in another article.

\section{Conclusions}

In conclusion, the incidence of presacral abscess after middle and low rectal cancer surgery is low, the symptoms are more insidious, the diagnosis is easy to miss, and the treatment is relatively tricky. How to avoid PA is very important. Through the Univariate Chi-square test and multivariate analysis, this study systematically analyzes the factors of occurrence of PA of middle and low rectal cancer. Patients with big tumor size, long operative time, high blood loss and preoperative radiotherapy are high-risk groups of presacral abscess of middle and low rectal cancer. Therefore, we believe that the measures can reduce the occurrence of PA to a certain extent, which including choosing surgical indications reasonably, rational operation timing and systematic and standardized operation training for surgeons.

\section{Declarations}

\section{Ethics approval and consent to participate}

The research carried out in this article was reviewed by the Changhai hospital ethics committee.

\section{Consent for publication}

All authors agree to publish the research content publicly.

\section{Availability of data and materials}

The datasets used and analysed during the current study are available from the corresponding author on reasonable request. 


\section{Competing interests}

All authors have no dispute over the attribution and no conflict of interest.

\section{Funding}

The research was funded by the hospital discipline construction project No: 2020 YXK034

\section{Authors' contributions}

Ang $L$ and Jun Shi contributed equally to this article. Correspondence to Xiaohui Shi.

\section{Acknowledgements}

The authors gratefully acknowledge the financial supports by the Changhai hospital. Useful suggestions given by Pro.Enda Yu of Changhai hospital are also acknowledged.

\section{References}

[1] Eckmann C, Kujath P, Schiedeck TH, et al. Anastomotic leakage following low anterior resection: results of a standardized diagnostic and therapeutic approach[J]. Int J Colorectal Dis, 2004,19(2):128133. DOI: $10.1007 / \mathrm{s} 00384-003-0498-8$.

[2] Rahbari NN, Weitz J, Hohenberger W, et al. Definition and grading of anastomotic leakage following anterior resection of the rectum: a proposal by the International Study Group of Rectal Cancer[J]. Surgery, 2010,147(3):339-351. DOI: 10.1016/j.surg.2009.10.012.

[3] Hyman N, Manchester TL, Osler T, et al. Anastomotic leaks after intestinal anastomosis: it's later than you think[J]. Ann Surg, 2007,245(2):254-258. DOI: 10.1097/01.sla.0000225083.27182.85.

[4] Robert B, Chivot C, Fuks D, et al. Percutaneous, computed tomography-guided drainage of deep pelvic abscesses via a transgluteal approach: a report on 30 cases and a review of the literature[J]. Abdom Imaging, 2013,38(2):285-289. DOI: 10.1007/s00261-012-9917-z.

[5] Konishi T, Watanabe T, Kishimoto J, et al. Risk factors for anastomotic leakage after surgery for colorectal cancer: results of prospective surveillance[J]. J Am Coll Surg, 2006,202(3):439-444. DOI: 10.1016/j.jamcollsurg.2005.10.019.

[6] Testini M, Margari A, Amoruso M, et al. [The dehiscence of colorectal anastomoses: the risk factors][J]. Ann Ital Chir, 2000, 71(4):433-440.

[7] Marusch F, Koch A, Schmidt U, et al. Value of a protective stoma in low anterior resections for rectal cancer[J]. Dis Colon Rectum, 2002, 45(9):1164-1171. DOI: 10.1007/s10350-004-6384-9. 
[8] Veenhof AA, Brosens R, Engel AF, et al. Risk factors and management of presacral abscess following total mesorectal excision for rectal cancer[J]. Dig Surg, 2009,26(4):317-321. DOI: 10.1159/000231882.

[9] Maas HA, Lemmens VE, Nijhuis PH, et al. Benefits and drawbacks of short-course preoperative radiotherapy in rectal cancer patients aged 75 years and older[J]. Eur J Surg Oncol, 2013, 39(10):10871093. DOI: 10.1016/j.ejso.2013.07.094.

[10] Vermeer TA, Orsini RG, Daams F, et al. Anastomotic leakage and presacral abscess formation after locally advanced rectal cancer surgery: Incidence, risk factors and treatment[J]. Eur J Surg Oncol, 2014,40(11):1502-1509. DOI: 10.1016/j.ejso.2014.03.019.

[11] Lorentzen T, Nolsøe C, Skjoldbye B. Ultrasound-guided drainage of deep pelvic abscesses: experience with 33 cases[J]. Ultrasound Med Biol, 2011,37(5):723-728. DOI: 10.1016/j.ultrasmedbio.2011.02.004.

\section{Tables}

Table 1 Single-factor analysis of presacral abscess after radical resection of rectal cancer

\begin{tabular}{|c|c|c|c|c|}
\hline Clinical features & $\begin{array}{c}\text { Abscess } \\
\text { group } \\
\text { (27 } \\
\text { cases) }\end{array}$ & $\begin{array}{c}\text { No abscess } \\
\text { group } \\
\text { ( } 2252 \\
\text { cases) }\end{array}$ & $x^{2}$ & $P$ value \\
\hline $\begin{array}{c}\text { Gender } \\
\text { (male / female) }\end{array}$ & $22 / 5$ & $1448 / 804$ & 3.440 & 0.064 \\
\hline $\begin{array}{c}\text { Age } \\
\text { (years old, }<60 / \geqslant \\
60 \text { ) }\end{array}$ & $14 / 13$ & $1128 / 1124$ & 0.033 & 0.855 \\
\hline $\begin{array}{l}\text { Tumor location } \\
(\mathrm{cm}, \leqslant 5 />5)\end{array}$ & $12 / 15$ & $1065 / 1187$ & 0.087 & 0.768 \\
\hline $\begin{array}{l}\text { Tumor maximum } \\
\text { diameter } \\
(\mathrm{cm}, \leqslant 4>4)\end{array}$ & $8 / 19$ & $1541 / 711$ & 18.447 & 0.000 \\
\hline $\begin{array}{c}\text { Operative time } \\
(\mathrm{min}, \quad<240 / \geqslant 240)\end{array}$ & $9 / 18$ & $1797 / 455$ & 35.019 & 0.000 \\
\hline $\begin{array}{c}\text { Blood loss } \\
(\mathrm{ml}, \leqslant 300 />300)\end{array}$ & $12 / 15$ & $1892 / 360$ & 30.388 & 0.000 \\
\hline $\begin{array}{l}\text { T stage lesions } \\
\left(\mathrm{T}_{1 \sim 2} / \mathrm{T}_{3 \sim 4}\right)\end{array}$ & $4 / 23$ & $828 / 1424$ & 4.640 & 0.031 \\
\hline $\begin{array}{l}\text { Lymph node metastasis } \\
\text { (no/ yes) }\end{array}$ & $15 / 12$ & $1342 / 910$ & 0.180 & 0.671 \\
\hline $\begin{array}{l}\text { Preoperative } \\
\text { radiotherapy } \\
\text { (no/ yes) }\end{array}$ & $21 / 6$ & $2086 / 166$ & 8.433 & 0.004 \\
\hline $\begin{array}{l}\text { Preventive terminal } \\
\text { ileostomy } \\
\text { (no / yes) }\end{array}$ & $5 / 22$ & $1214 / 1038$ & 13.432 & 0.000 \\
\hline
\end{tabular}


Table 2 Multivariate analysis of presacral abscess after radical resection of rectal cancer

\begin{tabular}{|c|c|c|c|c|}
\hline \multirow{2}{*}{ clinical features } & \multirow{2}{*}{$O R$} & \multicolumn{2}{|c|}{$95 \% C I$} & \multirow{2}{*}{$P$ value } \\
\hline & & 下限 & 上限 & \\
\hline Tumor maximum & & & & \\
\hline $\begin{array}{c}\text { diameter } \\
(\mathrm{cm}, \leqslant 4>4)\end{array}$ & 0.211 & 0.086 & 0.520 & 0.001 \\
\hline $\begin{array}{c}\text { Operative time } \\
(\min , \quad<240 / \geq 240)\end{array}$ & 0.128 & 0.054 & 0.301 & 0.000 \\
\hline $\begin{array}{c}\text { Blood loss } \\
(\mathrm{ml}, \leqslant 300 />300)\end{array}$ & 0.147 & 0.065 & 0.335 & 0.000 \\
\hline $\begin{array}{c}\mathrm{T} \text { stage lesions } \\
\left(\mathrm{T}_{1} \sim 2 / \mathrm{T}_{3} \sim 4\right.\end{array}$ & 0.383 & 0.122 & 1.202 & 0.100 \\
\hline $\begin{array}{l}\text { Preoperative } \\
\text { radiotherapy } \\
\text { (no/yes) }\end{array}$ & 0.195 & 0.069 & 0.549 & 0.002 \\
\hline $\begin{array}{c}\text { Preventive terminal } \\
\text { ileostomy } \\
\text { (no / yes) }\end{array}$ & 0.172 & 0.063 & 0.472 & 0.001 \\
\hline
\end{tabular}

\section{Supplementary Files}

This is a list of supplementary files associated with this preprint. Click to download.

- renamedae291.jpg 